\title{
Formação e mercado de trabalho dos jornalistas
}

\author{
Journalists' training and labor market \\ Formación y mercado laboral para periodistas
}

Jefferson Mariano

Faculdade Cásper Líbero

<jmariano@casperlibero.edu.br>

\section{Resumo}

0 estudo tem como objetivo analisar o comportamento do mercado de trabalho para profissionais jornalistas no Estado de São Paulo. Pretende contrastar a quantidade de estudantes egressos dos cursos de graduação com a quantidade de vagas oferecidas pelo mercado de trabalho. Desse modo, pretende sinalizar os limites da capacidade de absorção desse mercado. Paralelamente, contrasta as dificuldades de inserção dos jornalistas com os demais profissionais de nível superior. Incialmente há uma descrição do comportamento recente do mercado de trabalho brasileiro. Em seguida há detalhamento da metodologia utilizada, apontando as bases consultadas para realização do estudo. Por fim o estudo destaca os impactos da crise econômica ocorrida entre 2015 e 2016 e da reforma trabalhista, ocorrida em 2017.

Palavras- Chave: Comunicação Social. Jornalismo. Trabalho. Emprego.

\section{Abstract}

The study aims to analyze the behavior of the labor market for professional journalists in the State of São Paulo. It aims to contrast the number of students graduating from undergraduate courses with the number of places offered by the job market. In this way, it intends to signal the limits of the absorption capacity of that market. At the same time, it contrasts the difficulties of insertion of journalists with other professionals with higher education. Initially, there is a description of the recent behavior of the Brazilian labor market. Then there is a detailed description of the methodology used, pointing out the bases consulted for the study. Finally, the study highlights the impacts of the economic crisis that occurred between 2015 and 2016 and the labor reform that occurred in 2017.

Key Words: Social Communication. Journalism. Job.Employment

\section{Resumen}

El estudio tiene como objetivo analizar el comportamiento del mercado laboral de los periodistas profesionales en el estado de São Paulo. Se pretende contrastar el número de estudiantes provenientes de carreras de grado con el número de vacantes que ofrece el mercado laboral. De esta forma, pretende señalar los límites de la capacidad de absorción de este mercado. Al mismo tiempo, contrasta las dificultades de inserción de los periodistas con otros profesionales con estudios superiores. Inicialmente, se describe el comportamiento reciente del mercado laboral brasileño. Luego, se detalla la metodología utilizada, señalando las bases consultadas para el estudio. Finalmente, el estudio destaca los impactos de la crisis económica ocurrida entre 2015 y 2016 y la reforma laboral que tuvo lugar en 2017.

Palabras clave: Comunicación Social. Periodismo. Trabaja. Trabajo. 


\section{Apresentação}

O Brasil enfrentou no biênio 2015-2016 um processo acentuado de retração na atividade econômica. $\mathrm{O}$ mercado de trabalho foi uma face dessa tendência, uma vez que o número de pessoas desempregadas, segundo o IBGE, passou de 6,5 milhões em 2014 para 12,3 milhões no ano de 2017.

Mas a crise não foi marcada apenas pelo incremento de pessoas desocupadas. Aquelas que permaneceram ocupadas enfrentaram cenário de precarização, traduzido em redução da proteção social e menores rendimentos, aspectos que podem ser explorados nas edições da Pesquisa Nacional por Amostra de Domicílios Contínua (Pnadc), consultadas ao longo do trabalho.

A retração ocorreu em praticamente todos os setores de atividade econômica e apresentou algumas especificidades no segmento de comunicação. Grandes grupos econômicos nesse segmento passaram a enfrentar, além da crise, impactos decorrentes do acelerado processo de novas ferramentas de comunicação e tecnologia da informação (DIEESE).

No tocante às ocupações, observam-se também no referido mercado, reflexos da desregulamentação do mercado de trabalho em 2017, com o aumento no quantitativo de profissionais demitidos. Assim, há menor ocorrência de contratação com carteira assinada e o surgimento de formas alternativas de inserção no mercado, além da migração de profissionais para atividades não relacionadas ao segmento de comunicação.

Desse modo, o quadro desenhado coloca aos jornalistas e profissionais de comunicação desafios no tocante à inserção no mercado formal de trabalho e paralelamente a necessidade de incluir em seu processo de formação novas competências.

\section{Metodologia}

O trabalho procura responder à questão relativa aos limites de absorção pelo mercado dos profissionais egressos dos cursos de graduação em Jornalismo, em contraste com outras carreiras de nível superior, no estado de São Paulo.

Há, no âmbito das ciências sociais, intenso debate concernente às alterações no mercado de trabalho (BARCELLOS; MARIANO, 2019). No Brasil, o processo se intensificou especialmente a partir da crise econômica, iniciada em 2015, redundando nas mudanças da regulação do mercado de trabalho com a implementação da Lei n. 13.467 de 13 de julho de 2017. Paralelamente, observam-se também elementos relativos à qualidade da mão de obra disponível. Ou seja, parcela da desagregação do mercado de trabalho estaria localizada na baixa qualificação da força de trabalho, associada por sua vez ao reduzido nível de escolaridade ou de formação inadequada.

Nesse sentido, os saberes tratados nas escolas e universidades estariam em descompasso com as demandas existentes no mercado de trabalho. Desse modo, faz-se necessário observar se o fenômeno está presente exclusivamente no segmento de comunicação social ou se há uma generalização para outras carreiras de nível superior.

O estudo se desenvolve a partir da utilização do método dedutivo hipotético, tendo como base literatura no âmbito das ciências sociais aplicada.

O levantamento de informações para a realização do estudo ocorre a partir da utilização dos bancos de dados do sistema Rais/ Caged, do Ministério da Economia. A partir da análise dos microdados há uma leitura do comportamento de algumas ativida- 
des profissionais, no sentido de observar a evolução do fluxo de empregos. A construção de variáveis que permitem elaborar o perfil do profissional jornalista inserido no mercado de trabalho ocorrem também por meio da utilização dos microdados da Pesquisa Nacional por Amostra de Domicílios Contínua (Pnadc), com a comparação entre os anos de 2014, 2015 (início da recessão) e 2019. O objetivo é captar o impacto da crise econômica e das mudanças na regulação, ocorridas em final de 2017.

O quadro relativo ao número de jornalistas formados (concluintes dos cursos de graduação) é observado a partir de consulta as bases do Instituto Nacional de Estudos e Pesquisas Educacionais Anísio Teixeira (INEP). Ainda no tocante à manipulação de informações agregadas, para maior detalhamento de características de inserção de profissionais de nível superior no mercado de trabalho, ocorre análise de dados disponíveis no Censo Demográfico (IBGE). Trata-se da única base de dados que possibilita cruzamentos específicos e detalhados relativos à formação e à inserção no mercado de trabalho. A identificação de ocupações relacionadas no trabalho se dará a partir da consulta às bases da Classificação Brasileira de Ocupações (CBO).

Acredita-se que as ocupações relacionadas à área de comunicação tenham enfrentado os mesmos percalços observados no conjunto do mercado de trabalho brasileiro e aos demais profissionais de nível superior, especialmente no que se refere ao aumento da informalidade.

A partir do estabelecimento de correlação entre as variáveis disponíveis nas pesquisas consultadas, acredita-se que novas ocupações possam surgir como alternativas para o profissional de comunicação social. Também pretende-se observar similaridades com outras carreiras no tocante a buscas de alternativas no mercado de trabalho.

\section{Referencial Teórico}

A abordagem do tema proposto apresenta como eixos: caracterização e classificação da atividade comunicação social, aspectos da formação acadêmica do profissional jornalista e perfil do mercado de trabalho brasileiro.

A taxinomia das atividades econômicas é definida pela Classificação Nacional de Atividades Econômicas (CNAE), cuja gestão é de responsabilidade do IBGE. De acordo com a instituição,

As classificações são utilizadas como sistema de linguagem na produção de informações estatísticas, sendo a uniformização dessa linguagem condição imprescindível não só para a consistência das séries temporais e das comparações regionais e internacionais como também para a articulação entre sistemas de informações ou fontes distintas, que são pressupostos básicos da qualidade do sistema estatístico. (IBGE, 2019).

A CNAE indica a classificação da atividade econômica, ou seja, o endereço da empresa ou empreendimento na economia. Concernente às especificidades das tarefas desenvolvidas pelo profissional, a ferramenta de consulta deve ser a CBO, empregada nas pesquisas e sondagens do mercado de trabalho e nos cadastros do Sistema RAIS/Caged. A referida classificação per- 
mite relacionar as tarefas e rotinas associadas à profissão que se pretenda investigar. Ou seja, é possível saber em que medida um profissional jornalista inserido no mercado de trabalho se distancia das atividades relativas à sua formação.

O trabalho não tem como pretensão realizar longa cronologia acerca das transformações as quais o referido setor atravessa. Tampouco mergulhar no universo dos dilemas presentes na atividade do profissional jornalista. O objetivo é captar contribuições que possam corroborar a compreensão do movimento do mercado de trabalho e dificuldades que se apresentam para os esses profissionais. No tocante a essa dinâmica, Charron e Bonville (2016) sinalizam a existência de desequilíbrios na relação entre os consumidores, profissionais, anunciantes, fontes e o mercado financeiro. Chama atenção nessa análise a preocupação concernente ao impacto causado pela internet sobre o mercado. Nesse sentido deve-se destacar que a crise e as transformações no setor decorrem de ampla gama de condicionantes e seria prematuro localizar o problema apenas na dimensão tecnológica.

A regulamentação da profissão de jornalista, ocorrida em 1969 (ROCHA, 2008) pode ter contribuído para a maior presença de profissionais no mercado editorial bem como para expansão do ensino em nível de graduação. Todavia deve-se destacar que as universidades privadas são instituições movidas pela oportunidade e lucro. Por exemplo, em 2008 entrou em vigor a Lei Federal n. 11.684 que instituiu o retorno das disciplinas de filosofia e sociologia nos currículos de ensino médio. Essa medida provocou um grande crescimento na oferta de cursos de ciências sociais e formação de professores nas referidas disciplinas.

Assim, se inicialmente a demanda por mão de obra impele as instituições no sentido de criação e ampliação de vagas no ensino superior, percebem-se, em segundo momento, limites para inserção no mercado formal, especialmente em situações de retração econômica. Procurando identificar processos que sinalizam mudanças estruturais ocorridas no mercado para profissionais de jornalismo, Pereira e Adghirn (2015, p. 5) observam que,

Para que uma mudança seja considerada estrutural é preciso que ela seja suficientemente abrangente e profunda para alterar radicalmente o modo como determinada atividade é praticada e simbolicamente reconhecida/ definida pelos atores. Ou seja, uma mudança estrutural se contrapõe a um grupo de mudanças conjunturais e às microinovações que normalmente afetam aspectos específicos de uma prática social. Por exemplo, o lançamento de um novo jornal ou a introdução de um novo software de diagramação certamente altera o modo como o jornalismo é praticado, mas dificilmente pode ser o estopim de um processo de mudanças estruturais. Por outro lado, o aparecimento de uma nova mídia como a internet - ou uma crise generalizada nas empresas de comunicação oferece potencial para alterar uma dimensão mais profunda da prática jornalística.

Trata-se de movimentos que, aliados ao contexto macroeconômico e de regulação, 
podem influenciar alterações no mercado, com aumento de demissões e de maior incremento de trabalhadores sem vínculo formal de emprego.

As autoras chamam atenção também para o impacto das alterações tecnológicas no tocante à lógica de produção e compartilhamento de informação. Destacam que os leitores deixam de ter uma atitude passiva diante da notícia ao passo que além de buscar novos formatos de consumo de mídia, passam a interagir e produzir conteúdo.

\section{A formação de jornalista e o mercado}

Para verificar a capacidade de absorção pelo mercado do contingente de profissionais jornalistas, observou-se o quadro de formação, sintetizado no número de alunos egressos das escolas de comunicação. Nesse caso, o indicador utilizado foi o número de alunos, concluintes, que realizam o exame do Enade. Vale lembrar que a realização do referido exame passou a ser critério para a obtenção do diploma.

Os resultados de 2018, edição que contempla os cursos de comunicação social e jornalismo, indicam grande concentração dos formandos no eixo Sul-Sudeste do país. No presente exercício foi realizado um recorte das informações disponíveis no estado de São Paulo. De acordo com o cartograma, é possível constatar a concentração dos concluintes na cidade de São Paulo. Em segundo momento, percebe-se a ocorrência em localidades no entorno da Região Metropolitana ou cidades com presença de universidades públicas.

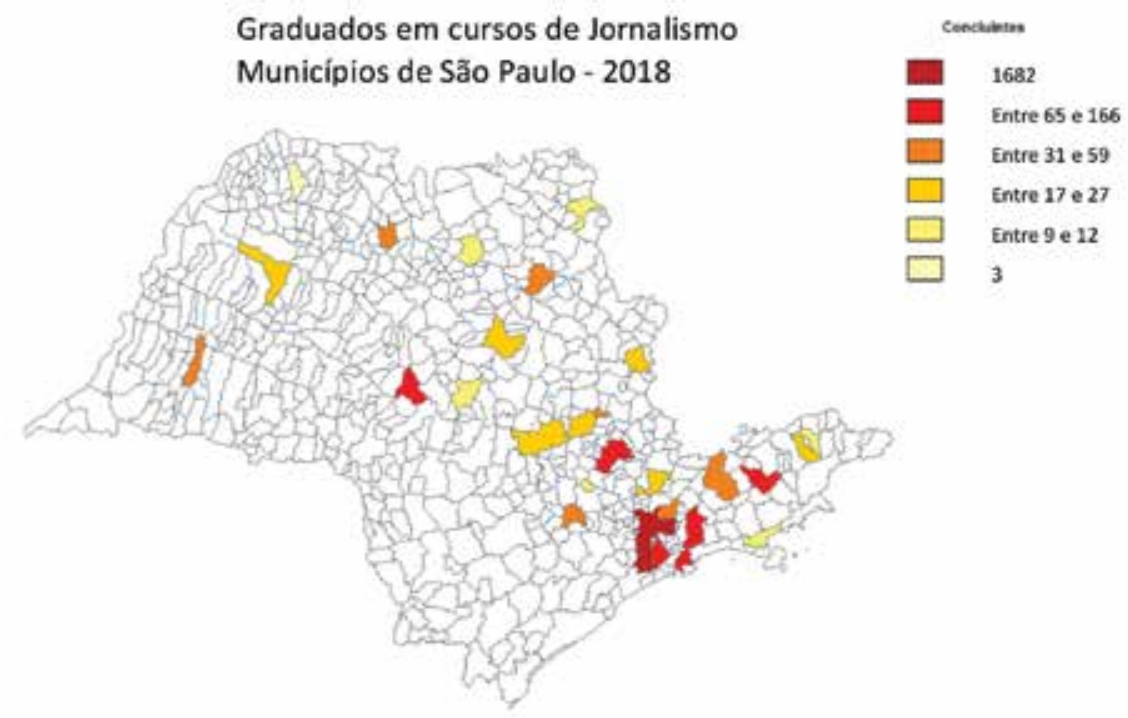

Inep: Censo escolar - 2018

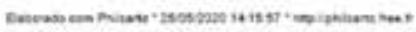

Figura 1 - Graduados em cursos de jornalismo - Municípios de São Paulo - 2018

Fonte: Inep - Censo escolar (2018). 
Apesar de a informação apresentar-se disponível nos arquivos, não se entra no mérito das notas obtidas no referido exame e que acabam por sinalizar a avaliação dos cursos. O objetivo, neste momento, é apresentar os totais de concluintes, para que seja possível aferir a capacidade que a estrutura econômica desses municípios apresenta, no sentido de absorver esses profissionais.

Como já destacado, as ocorrências de profissionais atuando como jornalistas apresentam-se em maior número na Pnadc do que no Caged, em razão de a primeira incorporar também os informais. No entanto, no Caged, há uma abertura mais detalhadas de ocupações correlatas à atividade do jornalista. Utilizam-se os dados de 2019, pois trabalha-se com pressuposto de que parcela dos concluintes em 2018 já se apresenta e exerce pressão sobre o mercado de trabalho.

Tabela 1 - Vagas abertas em atividades relacionadas à ocupação de jornalista - Estado de São Paulo - 2019

\begin{tabular}{|l|r|l|r|}
\hline \multicolumn{1}{|c|}{ Ocupações } & Vagas & \multicolumn{1}{c|}{ Ocupações } & Vagas \\
\hline Pesquisador informações de rede & 79 & Gravador de fotogravura & 13 \\
\hline Editor assistente & 63 & Administrador de arquivos & 10 \\
\hline Operador de scanner & 59 & Revisor de texto & 10 \\
\hline Montador de arte final & 37 & Tradutor & 9 \\
\hline Documentarista & 30 & Glossarista & 8 \\
\hline Editorialista & 27 & Editor de livro & 7 \\
\hline Repórter & 27 & Programador visual gráfico & 6 \\
\hline Produtor de texto & 26 & Diretor adjunto & 5 \\
\hline Fotógrafo & 24 & Editor de jornal & 5 \\
\hline Assessor de imprensa & 20 & Copiador de chapa & 3 \\
\hline Montador de fotocomposição & 19 & Adaptador de obras & 1 \\
\hline Comunicador de mídias audiovisuais & 18 & Arquivista pesquisador & 1 \\
\hline Bibliógrafo & 16 & Comentarista & 1 \\
\hline Editor de mídia eletrônica & 14 & Editor de revista & 1 \\
\hline Radio repórter & 14 & $\begin{array}{l}\text { Especialista na conservação de } \\
\text { acervos }\end{array}$ \\
\hline
\end{tabular}

Ministério da Economia: Cadastro Geral de Emprego e Desemprego - 2019.

Dados obtidos a partir dos microdados da pesquisa. 
Na Tabela 1 foram listadas ocupações diretamente relacionadas à carreira de jornalista, seguindo o código CBO. No total, foram observadas 555 vagas abertas enquadradas nessa categoria, no estado de São Paulo em 2019. É possível que parcela significativa de profissionais jornalistas consiga inserção em outras atividades não diretamente relacionais à formação e que, em grande medida, essas vagas apresentem como pré-requisito a posse de diploma de nível superior. Por exemplo, em concursos públicos é muito comum a exigência de formação superior, sem necessariamente indicação de área específica.

Porém, não restam dúvidas de que há uma distância expressiva relativa à oferta de oportunidades de trabalho formal na área em contraste com o contingente de jornalistas aptos a compor esse mercado.

Em pesquisa realizada pelo Departamento Intersindical de Estatística e Estudos Socioeconômicos (DIEESE), observando o estoque de empregos, ou seja, o contingente de todos os profissionais jornalistas inseridos no mercado, há uma indicação da redução na presença de profissionais jornalistas no mercado formal. A pesquisa, disponibilizada no Portal dos Jornalistas, levanta informações de várias fontes, porém foram enfatizados os dados obtidos no Relatório Anual de Informações Sociais (RAIS).

Os números apresentam um grande volume, quando comparadas as vagas disponibilizadas (critério adotado no presente trabalho), justamente por se tratar do estoque de profissionais atuando. De acordo com essa pesquisa, havia em
2014 um estoque de 16.972 profissionais atuando como jornalista no estado de São Paulo e em 2018 o número chegou a 13.604.

Ressalte-se a relevância dessa pesquisa, pois sinaliza a redução de trabalhadores ocupando cargos relacionados à atividade de jornalista, captando transformações ocorridas no universo da categoria e impactos decorrentes da crise econômica entre 2015 e 2017. O relatório credita parcela dessas mudanças às alterações no mercado, redundando em crise e fechamento de algumas empresas. Chama atenção para o fato da forte concorrência com as mídias digitais, que inclusive não são caracterizadas como empresas de comunicação, mas de tecnologia e desse modo, não se submetem às regras estabelecidas para o setor.

No presente estudo, os dados foram organizados seguindo outros critérios. Em um primeiro momento foram explorados os dados disponíveis do Caged, com objetivo de perceber o comportamento do fluxo de empregos. Ou seja, observar a quantidade de vagas oferecidas para que seja possível contrastar com a quantidade de estudantes egressos dos cursos de graduação.

Segundo os dados do Inep, em São Paulo, no ano de 2018, foram observados 3.063 concluintes dos cursos de graduação, inscritos no Exame Nacional de Desempenho (Enade), ao passo que, em 2019, foram oferecidas 555 vagas no mercado de trabalho para atividades compatíveis com essa formação. Ou seja, os números apontam um elevado déficit quando observadas atividades típicas desse profissional. 
A leitura desses dados pode ser realizada observando um contexto mais abrangente, ou na terminologia de pesquisa, considerando como variável moderadora o quadro geral do comportamento do mercado formal de trabalho no Brasil para profissionais de nível superior.

Nesse caso, para que fosse possível reunir um conjunto de dados mais expressivos, além da possibilidade de comparação entre as demais carreiras de nível superior, foram selecionadas ocorrências da Pnadc em nível territorial Brasil. No entanto, caso a escolha fosse o recorte territorial São Paulo, haveria para algumas carreiras um número limitado de eventos, comprometendo a análise dos resultados. Desse modo, a Tabela 2 apresenta a evolução de vagas no mercado de trabalho, segundo carreiras de nível superior entre 2015 e 2019.

Os números descrevem que, a partir de 2015, com o início do quadro recessivo da economia brasileira, observa-se uma queda bastante acentuada em algumas ocupações de nível superior. Nesse sentido, vários elementos podem contribuir para o cenário. Além da crise econômica e o processo de desregulamentação do mercado de trabalho existem aspectos relativos à natureza de algumas atividades. Algumas carreiras ligadas a setores que passaram por processos de inovação tecnológica podem ter perdido espaço no mercado de trabalho. Nesse sentido, os números apontam que, a despeito do que se apresenta em algumas áreas de atuação, a carreira de jornalismo não seria a mais afetada pelo processo. Muitas atividades ligadas ao setor industrial perderam espaço expressivo, provavelmente em decorrência do ciclo de encolhimento na participação do setor no Produto Interno Bruto.

Além desse grupamento, algumas atividades estritamente acadêmicas, como as de físicos e matemáticos, perderam espaço significativo no mercado de trabalho. Chama atenção a queda expressiva no caso de sociólogos e antropólogos. Nesse caso, o número de observações em 2019 foi tão reduzido que o sistema não possibilitou a expansão da amostra para que fosse possível obter o resultado. Ocupações relacionadas à atividade de jornalismo ficaram em posição intermediária nesse rol e apresentaram um crescimento nominal de 35,8\% entre 2015 e 2019 . Ressalte-se que nesse grupamento não estão inseridos os profissionais jornalistas que atuam no mercado como docentes de nível superior. Também importante destacar a evolução do emprego ao longo do período. Entre 2015 e 2019, houve aumento de apenas 3,0\% no total de pessoas ocupadas no país, considerando inclusive a participação de pessoas inseridas de modo informal. 
Tabela 2 - Pessoas ocupadas segundo carreiras de nível superior - Brasil - 2015/2019

\begin{tabular}{|c|c|c|c|}
\hline \multirow[b]{2}{*}{ Ocupações } & \multicolumn{3}{|c|}{ Pessoas ocupadas } \\
\hline & 2015 & 2019 & $\begin{array}{c}\text { Variação } \\
(\%)\end{array}$ \\
\hline Sociólogos e antropólogos & 1.331 & $*$ & \\
\hline Engenheiros químicos & 15.815 & 6.209 & $-60,7$ \\
\hline Físicos & 3.252 & 1.885 & $-42,0$ \\
\hline Engenheiros mecânicos & 36.701 & 22.024 & $-40,0$ \\
\hline Professores ensino superior & 97.572 & 62.528 & $-35,9$ \\
\hline Matemáticos e estatísticos & 2.734 & 1.771 & $-35,2$ \\
\hline Engenheiros eletricistas & 25.625 & 17.807 & $-30,5$ \\
\hline Engenheiros industriais & 27.598 & 26.760 & $-3,0$ \\
\hline Médicos especialistas & 91.533 & 94.299 & 3,0 \\
\hline Biólogos e botânicos & 13.702 & 14.512 & 5,9 \\
\hline Veterinários & 15.376 & 16.549 & 7,6 \\
\hline Médicos gerais & 25.725 & 29.176 & 13,4 \\
\hline Psicólogos & 61.876 & 73.586 & 18,9 \\
\hline Analistas de sistemas & 89.590 & 107.978 & 20,5 \\
\hline Engenheiros Civis & 51.004 & 61.497 & 20,6 \\
\hline Arquitetos de edificações & 35.817 & 44.700 & 24,8 \\
\hline Farmacêuticos & 43.033 & 53.709 & 24,8 \\
\hline $\begin{array}{l}\text { Profissionais de } \\
\text { enfermagem }\end{array}$ & 71.963 & 94.363 & 31,1 \\
\hline Jornalistas & 34.891 & 47.366 & 35,8 \\
\hline Economistas & 7.275 & 10.282 & 41,3 \\
\hline Químicos & 11.455 & 18.004 & 57,2 \\
\hline Dentistas & 59.627 & 100.679 & 68,8 \\
\hline Contadores & 81.828 & 152.659 & 86,6 \\
\hline Assistentes sociais & 13.438 & 25.387 & 88,9 \\
\hline Total de pessoas ocupadas & 91.800 .000 & 94.552 .000 & 3,0 \\
\hline
\end{tabular}

IBGE: Pesquisa Nacional por Amostra de Domicílios Contínua. Microdados da pesquisa.

*Ocorrências muito reduzidas, que não permitem a expansão da amostra em função do sigilo da informação e erro amostral. 
Taxas de desocupação por nível de escolaridade (\%)

25

Brasil - 4을 trimestre 2012/2019

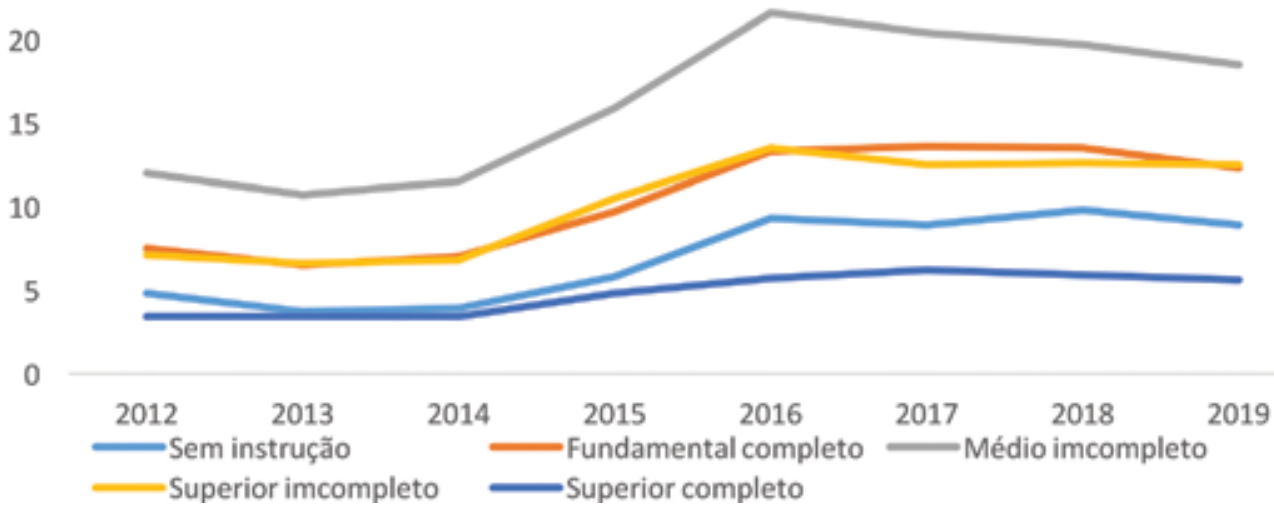

Figura 2 - Taxas de desocupação por nível de escolaridade (\%) - Brasil - $4^{0}$ trimestre 2012/2019.

Fonte: IBGE - Pesquisa Nacional por Amostra de Domicílios Contínua

Desse modo, apesar da dificuldade de inserção do mercado de trabalho, os indicadores apontam que, ainda assim, o diploma de nível superior torna-se um diferencial importante. Os níveis de ocupação, considerando a escolaridade, são historicamente mais elevados para pessoas de nível superior e esse comportamento está ocorre desde o início das pesquisas realizadas no Brasil.

No caso específico dos trabalhadores sem instrução, merece explicação o fato de os níveis baixos de desocupação estarem diretamente associados à flexibilidade no tocante às ocupações disponíveis. Nesse estágio, os trabalhadores, em razão de realizarem as tarefas mais elementares disponíveis no mercado, encontram barreiras reduzidas entre os setores. Ou seja, há maior mobilidade intrasetorial. Paradoxalmente, na medida em que ocorre aumento de escolaridade os trabalhadores passam a ocupar segmentos específi- cos das cadeias produtivas e, desse modo, buscam oportunidades de trabalho em um universo mais restrito. No outro extremo, em razão de ainda do número reduzido de pessoas com nível superior, percebe-se um diferencial no tocante às taxas de desocupação.

No entanto, é importante observar a natureza das ocupações destinadas aos trabalhadores de nível superior no país. Como foi possível observar, há uma distância significativa entre o número de formandos em jornalismo no estado de São Paulo e a oferta de ocupações compatíveis com essa formação. Os números levantados pelo Caged, dispostos na Tabela 1 , indicam um enorme hiato entre esses dois fenômenos. Os dados apontam para dois possíveis cenários: desestruturação do mercado de trabalho, fato que pode ser observado quando analisado o comportamento das demais carreiras de nível superior. Ou seja, há elevado número de 
trabalhadores ocupados de modo informal, além do crescente número de subutilizados. Em 2019, segundo a Pnadc a taxa de informalidade do mercado de trabalho correspondia a 41,1\% no Brasil e 32,2\% no estado de São Paulo 32,2\%.

Há também possibilidade de indicar um problema estrutural, relacionado à capacidade das instituições de ensino no sentido de preparar os recém-formados para o ingresso no mercado de trabalho. Nesse caso, é importante destacar que não se trata de um fenômeno exclusivo do Brasil. Há muitos países que vêm discutindo a necessidade de aproximação da universidade com os mercados. Pesquisa divulgada pela Pearson Educacional em 2019 aponta que, em praticamente todos os países nos quais a pesquisa foi aplicada, existe a percepção de que os sistemas educacionais não estão atendendo às demandas sociais, especialmente no caso das novas gerações (PEARSON, 2019).

\section{A inserção distante da formação}

Partindo da observação de ocorrências no Censo Demográfico 2010, relativas ao tema estudado, foi realizada uma tabulação para verificar a inserção no mercado das mais diversas formações de nível superior. Destaca-se que só é possível realizar essa combinação de dados no Censo em razão do detalhamento das questões. O objetivo do cruzamento é observar as ocupações das pessoas inseridas no mercado de trabalho em algumas carreiras de nível superior listadas. Em função do grande número de carreiras optou-se por realizar a seleção a partir de grandes agrupamentos.
Na seleção inicial a preocupação foi observar a distribuição dos profissionais jornalistas no mercado de trabalho no estado de São Paulo. Como já destacado na Tabela 1, no ano de 2019 foram abertas 381 vagas de emprego em atividades diretamente relacionadas as ocupações de jornalistas.

Os dados organizados na Tabela 3 permitem observar a distribuição de profissionais com formação em jornalismo nas mais diversas atividades econômicas. Algumas ocupações estão relacionadas à mobilidade no interior das estruturas coorporativas, como é o caso de diretores e dirigentes da administração pública e privada. Também se observam muitos profissionais com graduação em jornalismo atuando em ocupações de nível superior, no entanto, em outras carreiras. Em relação a esse aspecto, há um conjunto de trabalhadores que, mesmo concluindo o curso de nível superior, permanece no emprego ao qual estava vinculado durante o processo de formação. Significa dizer que o título de nível superior garante a um grupo de trabalhadores a empregabilidade. Ou seja, mesmo que não obtenha vaga na carreira, permanece empregado. A explicação pode estar localizada nos baixos índices de desemprego entre profissionais de nível superior. Por outro lado, é importante destacar a reduzida presença de profissionais jornalistas em ocupações elementares, nas quais escolaridade não é um pré-requisito determinante.

Para contrastar esse comportamento com outras carreiras buscou-se, a partir do mesmo conjunto de dados, organizar uma série de ocupações elementares segundo presença de pessoas com formação superior. 
Tabela 3 - Pessoas graduadas em Jornalismo, segundo ocupação principal - Estado de São Paulo - 2010

\begin{tabular}{|c|c|c|c|}
\hline Ocupação principal & Pessoas & Ocupação principal & Pessoas \\
\hline $\begin{array}{l}\text { Profissionais em direito, ciências sociais } \\
\text { e culturais }\end{array}$ & 20.245 & $\begin{array}{l}\text { Diretores, dirigentes da } \\
\text { administração pública e membros do } \\
\text { poder Executivo e Legislativo }\end{array}$ & 573 \\
\hline Dirigentes administrativos e comerciais & 4.695 & Trabalhadores dos serviços pessoais & 498 \\
\hline $\begin{array}{l}\text { Especialistas em organização da } \\
\text { administração pública e de empresas }\end{array}$ & 4.076 & Profissionais da saúde & 334 \\
\hline $\begin{array}{l}\text { Profissionais de nível médio em } \\
\text { operações financeiras/administrativas }\end{array}$ & 3.765 & $\begin{array}{l}\text { Profissionais de nível médio das } \\
\text { ciências e da engenharia }\end{array}$ & 322 \\
\hline Escriturários & 3.470 & $\begin{array}{l}\text { Condutores de veículos e operadores } \\
\text { de equipamentos móveis pesados }\end{array}$ & 322 \\
\hline Profissionais do ensino & 2.618 & $\begin{array}{l}\text { Profissionais de nível médio da saúde } \\
\text { e afins }\end{array}$ & 298 \\
\hline Vendedores & 2.363 & $\begin{array}{l}\text { Outros trabalhadores de apoio } \\
\text { administrativo }\end{array}$ & 240 \\
\hline $\begin{array}{l}\text { Dirigentes e gerentes de produção e } \\
\text { operação }\end{array}$ & 2.190 & Trabalhadores dos cuidados pessoais & 238 \\
\hline $\begin{array}{l}\text { Trabalhadores de atendimento direto ao } \\
\text { público }\end{array}$ & 1.319 & Artesãos e operários das artes gráficas & 229 \\
\hline $\begin{array}{l}\text { Técnicos de nível médio da tecnologia } \\
\text { da informação e das comunicações }\end{array}$ & 1.251 & $\begin{array}{l}\text { Trabalhadores dos serviços de } \\
\text { proteção e segurança }\end{array}$ & 219 \\
\hline $\begin{array}{l}\text { Gerentes de hotéis, restaurantes, } \\
\text { comércios e outros serviços }\end{array}$ & 945 & $\begin{array}{l}\text { Operários e oficiais de processamento } \\
\text { de alimentos, da madeira, da } \\
\text { confecção e afins }\end{array}$ & 164 \\
\hline $\begin{array}{l}\text { Profissionais de nível médio de serviços } \\
\text { jurídicos, sociais, culturais e afins }\end{array}$ & 944 & $\begin{array}{l}\text { Operadores de instalações fixas e } \\
\text { máquinas }\end{array}$ & 160 \\
\hline $\begin{array}{l}\text { Profissionais das ciências e da } \\
\text { engenharia }\end{array}$ & 865 & $\begin{array}{l}\text { Trabalhadores qualificados e } \\
\text { operários da metalurgia, da } \\
\text { construção mecânica e afins }\end{array}$ & 143 \\
\hline $\begin{array}{l}\text { Trabalhadores de cálculos numéricos e } \\
\text { encarregados do registro de materiais }\end{array}$ & 708 & $\begin{array}{l}\text { Trabalhadores domésticos e outros } \\
\text { trabalhadores de limpeza de interior } \\
\text { de edifícios }\end{array}$ & 141 \\
\hline $\begin{array}{l}\text { Profissionais de tecnologias da } \\
\text { informação e comunicações }\end{array}$ & 698 & $\begin{array}{l}\text { Trabalhadores elementares da } \\
\text { mineração, da construção, da } \\
\text { indústria de transformação e do } \\
\text { transporte }\end{array}$ & 105 \\
\hline
\end{tabular}

IBGE: Censo Demográfico 2010. Resultados amostra. 
Tabela 4 - Pessoas com graduação, segundo ocupação no trabalho principal - Graduação e ocupações selecionadas. Estado de São Paulo - 2010

\begin{tabular}{|l|r|r|r|r|r|r|r|r|r|}
\hline \multirow{2}{*}{\multicolumn{1}{|c|}{ Área de Graduação }} & \multicolumn{7}{|c|}{ Ocupação no trabalho principal } \\
\cline { 2 - 10 } & \multicolumn{1}{|c|}{ A } & \multicolumn{1}{c|}{ B } & \multicolumn{1}{c|}{ C } & \multicolumn{1}{c|}{ D } & \multicolumn{1}{c|}{ E } & \multicolumn{1}{c|}{ F } & \multicolumn{1}{c|}{ G } & H & \multicolumn{1}{c|}{ I } \\
\hline Arquitetura e Construção & 109 & 137 & 420 & 1.293 & 94 & 207 & 2.732 & $*$ & 371 \\
\hline Artes & 510 & 108 & 235 & 2.299 & 485 & 397 & 2.007 & $*$ & 759 \\
\hline Ciências da Vida & 68 & 66 & 386 & 2.243 & 214 & 1.947 & 1.791 & $*$ & 385 \\
\hline Ciências Físicas & 73 & 74 & 385 & 1.167 & 331 & 478 & 1.797 & $*$ & 337 \\
\hline Ciências sociais e comportamentais & 210 & 150 & 538 & 6.755 & 341 & 756 & 9.931 & 106 & 1.010 \\
\hline Comércio e Administração & 1.633 & 1.462 & 7.513 & 83.386 & 3.994 & 4.296 & 82.513 & 789 & 7.250 \\
\hline Computação & 197 & 209 & 633 & 6.400 & 608 & 470 & 5.884 & 81 & 582 \\
\hline Direito & 257 & 356 & 1.480 & 11.558 & 592 & 1.198 & 22.406 & 202 & 1.480 \\
\hline Engenharia e Profissões Correlatas & 448 & 321 & 1.229 & 3.329 & 1.572 & 1.080 & 8.150 & 136 & 640 \\
\hline Formação de Professores & 748 & 866 & 2.411 & 19.831 & 1.715 & 3.513 & 11.630 & 303 & 4.870 \\
\hline Humanidades e Letras & 234 & 208 & 739 & 9.889 & 619 & 1.062 & 7.132 & $*$ & 1.939 \\
\hline Jornalismo e Informação & 229 & 95 & 322 & 3.470 & 160 & 298 & 3.765 & $*$ & 498 \\
\hline Matemática e Estatística & $\mathrm{N} / \mathrm{C}$ & 75 & 433 & 2.164 & 168 & 205 & 2.545 & $*$ & 287 \\
\hline Saúde & 282 & 442 & 1.530 & 8.408 & 610 & 17.731 & 6.409 & 162 & 3.361 \\
\hline Serviço Social & $*$ & 46 & 94 & 1.490 & $*$ & 253 & 1.281 & $*$ & 342 \\
\hline
\end{tabular}

IBGE: Censo Demográfico 2010. Resultados da amostra

*Valores muito reduzidos, que não permitem a expansão do resultado.

Legenda das categorias na coluna:

A - Artesãos e operários das artes gráficas

$\mathrm{B}$ - Coletores de lixo e outras ocupações elementares

C - Condutores de veículos e operadores de equipamentos móveis pesados

D - Escriturários

E - Operadores de instalações fixas e máquinas

F - Profissionais de nível médio da saúde e afins

G - Profissionais de nível médio em operações financeiras e administrativas

$\mathrm{H}$ - Trabalhadores ambulantes dos serviços e afins

I - Trabalhadores dos serviços pessoais

Na Tabela 4, a preocupação foi a de selecionar atividades que não se enquadravam em ocupações de nível superior. Percebe-se, a partir da leitura dos dados, que existem algumas carreiras que formam um número muito elevado de graduados, como direito, administração e ciências contábeis.
As informações disponíveis auxiliam a levantar a hipótese de que, no caso dessas carreiras, há de fato uma grande empregabilidade. Ou seja, graduados nesses cursos conseguem facilmente inserção no mercado de trabalho. No entanto, a leitura dos dados sugere que em grande medida essa inserção 
ocorra nas ocupações de nível médio e intermediário.

Por exemplo, em cursos relacionados à área de administração e contabilidade, aproximadamente 88 mil pessoas no estado de São Paulo estavam ocupando o cargo de escriturários e 86 mil inseridas como profissionais de nível médio em atividades financeiras. Entre graduados em direito, observa-se o mesmo fenômeno, pois cerca de 22 mil também atuavam em ocupações de nível médio em atividades financeiras. Vale observar a existência de um pequeno grupo de profissionais na área de direito, ciências sociais, formação de professores e engenheiros atuando como ambulantes. Ou seja, apesar do número reduzido de ocorrências, sinaliza limitações no tocante à inserção no mercado de trabalho para alguns grupos.

Por fim, é importante destacar os impactos da crise econômicas de 2015 e 2016 sobre o comportamento do mercado de trabalho para profissionais jornalistas. Esse fato pode ser observado nas atividades com maiores frequências na Tabela 5.

Percebe-se que em algumas funções há um comportamento muito próximo no que se refere ao quantitativa de contratações ocorridas. Há evidentemente, descompasso entre algumas ocupações. No entanto, percebe-se que em ocupações como repórter, editor e assessor de imprensa, ocorre um aumento entre 2014 e 2019.

Tabela 5 - Vagas abertas em atividades relacionadas à ocupação de jornalista - Estado de São Paulo - 2014-2015 e 2019

\begin{tabular}{|c|c|c|c|}
\hline \multirow{2}{*}{ Ocupações } & \multicolumn{3}{|c|}{ Número de vagas criadas } \\
\hline & 2014 & 2015 & 2019 \\
\hline Pesquisador de informações de rede & 73 & 0 & 79 \\
\hline Administrador de arquivos & 66 & 0 & 10 \\
\hline Editor assistente & 51 & 2 & 63 \\
\hline Montador de arte final & 43 & 4 & 37 \\
\hline Editorialista & 38 & 3 & 27 \\
\hline Montador de fotocomposição & 31 & 0 & 19 \\
\hline Operador de scanner & 29 & 3 & 59 \\
\hline Revisor de texto & 25 & 1 & 10 \\
\hline Fotógrafo & 25 & 1 & 24 \\
\hline Gravador de fotogravura & 22 & 2 & 13 \\
\hline Repórter & 21 & 3 & 27 \\
\hline Documentarista & 21 & 0 & 30 \\
\hline Assessor de imprensa & 19 & 0 & 20 \\
\hline Comunicador de mídias audiovisuais & 18 & 2 & 18 \\
\hline
\end{tabular}

Ministério da Economia: Cadastro Geral de Emprego e Desemprego - 2014/2019.

Dados obtidos a partir dos microdados da pesquisa. 
Por outro lado, em 2015 não há praticamente abertura de postos de trabalho para esses profissionais. Ou seja, o setor foi um dos mais afetados pela crise. No entanto, como destacado anteriormente, parcela dos profissionais com graduação superior integrou o mercado de trabalho em outras ocupações. E os dados disponibilizados pelo levantamento indicam que é maior a ocorrência de pessoas com formação em jornalismo em ocupações de nível superior, quando comparadas com as demais carreiras listadas.

No presente artigo, dado que o objetivo é o de caracterizar o mercado de trabalho para os profissionais no jornalismo, não foi oferecido um detalhamento referente ao perfil dos profissionais que não lograram êxito em atuar nas atividades típicas de jornalistas, tampouco analisou-se a presença de profissionais de nível superior em ocupações de nível médio e intermediário. Acredita-se que, se realizados mais alguns ajustes finos no tocante ao levantamento dos dados, seria possível localizar dilemas relacionados a questões raciais e de gênero.

\section{Considerações finais}

O estudo teve como objetivo observar limites com relação à inserção de profissionais jornalistas no mercado de trabalho. Tendo como ponto de partida a severa crise econômica que o país enfrentou entre 2015-2016, procurou-se analisar de que modo houve impacto sobre a atividade desse profissional. Observou-se que a crise provocou uma intensa desaceleração da atividade econômica e impactou diretamente grandes grupos econômicos midiáticos.
A resposta foi o aumento das taxas de desemprego e redução dos postos de trabalho. Paralelamente, observou-se aumento da precarização do mercado de trabalho, sintetizada pela elevada taxa de informalização da economia. O texto aponta também que a reforma trabalhista, implementada em 2017, contribuiu para o incremento de trabalhadores inseridos no mercado informal. Os dados levantados pelo estudo corroboram a hipótese inicial de que a área de comunicação, e em específico o jornalismo, enfrenta as mesmas dificuldades que se apresentam aos demais profissionais de nível superior, especialmente no tocante à presença da informalidade e à inserção no mercado.

O estudo aponta que, a despeito da existência de um hiato entre o número de graduados em jornalismo e a quantidade de vagas disponibilizadas no mercado, existe uma grande presença desses profissionais em ocupações de nível superior. Por outro lado, quando se contrasta com outras carreiras, percebe-se que é menor a ocupação de jornalistas em atividade que prescindem do título de graduação.

Desse modo, indica-se que além da demanda ainda existente para esses profissionais, aspectos relativos ao conjunto de saberes e conhecimentos adquiridos ao longo da formação os credenciam a atuar em áreas não diretamente relacionadas à produção de informação. No entanto, apontam-se as fragilidades do mercado de trabalho traduzidas pelo elevado grau de informalidade. Ou seja, a crise econômica, aliada à desregulamentação do mercado de trabalho, contribuiu para a configuração do atual cenário. 


\section{Referências bibliográficas}

BARCELLOS, Lívia Inglesis; MARIANO, Jefferson. Mudanças na regulação do mercado de trabalho no Brasil. ORG \& DEMO, Marília, v. 20, n. 2, p. 65-84, jul./dez. 2019.

CHARRON, J.; BONVILLE, J. Natureza e transformação do jornalismo. Florianópolis: Ed. Insular, 2016.

IHITZ, Greetchen Ferreira. Jornalistas profissionais e os desafios da contemporaneidade nas empresas de comunicação. Revista Temática, v.11, n.5, p. 1-24, mai/ 2015. Disponível em: https://periodicos.ufpb.br/ojs/index.php/tematica/article/view/24362/13351

INSTITUTO BRASILEIRO DE GEOGRAFIA E ESTAÍSTICA (IBGE). Censo Demográfico 2010. Rio de Janeiro, 2012. Resultados gerais da amostra. Microdados. Disponível: https://www.ibge.gov.br/estatisticas/sociais/populacao/9662-censo-demografico-2010. html $=\& \mathrm{t}=$ microdados. Acesso em: 30 maio 2020.

INSTITUTO BRASILEIRO DE GEOGRAFIA E ESTAÍSTICA (IBGE). Pesquisa Nacional por Amostra de Domicílios Contínua. Rio de Janeiro, 2019. Microdados. Disponível em: https://www.ibge.gov.br/estatisticas/sociais/trabalho/9171-pesquisa-nacional-por-amostra-de-domicilios-continua-mensal.html?=\&t=microdados. Acesso em: 30 maio 2020.

INSTITUTO BRASILEIRO DE GEOGRAFIA E ESTAÍSTICA (IBGE). Classificação Nacional de Atividade Econômica. Rio de Janeiro, 2019. Disponível em: https://servicodados.ibge.gov.br/api/docs/cnae?versao=2. Acesso em: 15 jan. 2020.

PEARSON EDUCACIONAL. Global Learner Survey. 2019. Disponível em: https://entretantoeducacao.com.br/educacao/educacao-caminha-para-aprendizado-self-service-aponta-pesquisa/

PEREIRA, Fábio Henrique; ADGHIRNI, Zélia Leal. Jornalismo em tempos de mudanças estruturais. Intexto, Porto Alegre: UFRGS, v. 1, n. 24, p. 38-57, janeiro/junho 2011.

PORTAL DOS JORNALISTAS. Mercado formal do jornalismo encolhe em SP. São Paulo, 2020. Disponível em: https://www.portaldosjornalistas.com.br/mercado-formal-do-jornalismo-encolhe-em-sp-diz-pesquisa/. Acesso em: 30 maio 2020.

ROCHA, P. M.; SOUSA, J. P. Rumos do Jornalismo na Sociedade Digital: Brasil e Portugal. Porto: Universidade Fernando Pessoa, 2008.

Data do recebimento: 20/11/2020

Data do aceite: $15 / 03 / 2021$

Dados do autor:

\section{Jefferson Mariano}

Lattes: http://lattes.cnpq.br/3745579607334254

Dr. em Desenvolvimento Econômico, Mestre em Economia Política e Bacharel em Sociologia e Ciência Política.

Professor da Faculdade Casper Líbero e Analista Socioeconômico no IBGE. 